\title{
Identifying volcanic signals in Irish temperature observations since AD 1800
}

\author{
Stephen D. Galvin*, Kieran R. Hickey and Aaron P. Potito \\ School of Geography and Archaeology, National University of Ireland Galway, Ireland
}

\begin{abstract}
Large volcanic eruptions have been shown to affect temperature patterns to varying degrees on continental, hemispheric or global scales. However, few studies have systematically explored the influence of volcanic eruptions on temperatures at a local, Irish level. The focus of this paper is to determine the impacts of five high-magnitude low-latitude volcanic eruptions and one such Icelandic event on Irish climate over the past $\sim 200$ years. Daily temperature data from the Armagh Observatory, Co. Armagh, Northern Ireland was used to assess the influence of volcanic eruptions on seasonal and yearly values through time. The paper explores volcanically-induced temperature trends by filtering out the influence of the North Atlantic Oscillation (NAO) and solar variability, and goes on to employ a variation of Superposed Epoch Analysis to identify which seasons and years are most significantly affected by large volcanic eruptions. Armagh temperatures proved particularly responsive in the spring, with a significant decrease in values in the four years following an eruption. Winter temperatures also exhibited a volcanic influence, with a small initial increase in the year of and year following an eruption, and a significant decrease in residual temperature in years two and three after the event.
\end{abstract}

Keywords: Armagh; temperature; volcano; low-latitude; Iceland

\section{Introduction}

Global warming and the influence of anthropogenic changes to the environment are dominant themes in climate research today. However, the changes brought about by these processes have the potential to be abruptly altered by the impact of highmagnitude volcanic eruptions, particularly those at the lower latitudes. The injection of volcanic matter into the atmosphere has the ability to influence temperatures on a global scale. Volcanic events of varying intensity have the potential to lower global values by between $0.2^{\circ} \mathrm{C}$ and $0.5^{\circ} \mathrm{C}$ for one to three years after the eruption (Self et al. 1981). Such seemingly slight alterations in global temperatures can nonetheless have a prominent influence on regional weather, agriculture and society.

There is a tendency in the study of volcano-climate interactions to focus on widespread changes, with research by, amongst others, Pollack et al. (1993), Robock and Liu (1994), Robock (2000), Zielinski (2000) and de Silva (2005), examining continental, hemispheric or global changes in the wake of volcanic events. Písek and Brázdil (2006) point out that there needs to be more attention paid to the climatic effects of eruptions on a local level. At this scale volcanic signals have the potential to

*Corresponding author. Email: s.galvin3@nuigalway.ie 
manifest in a different manner than they do on a hemispheric or global scale due to the influence of local topographic and circulation patterns.

Studies of volcanic impacts on Irish climate are rare. Carbon isotopes in tree rings were used to assess causes for growth anomalies following the eruptions of Laki (Iceland, 1783) and Tambora (Indonesia, 1815) (Ogle et al. 2005). Ireland was also included in a review of first-hand accounts of hardships suffered following the 1815 Tambora eruption (Oppenheimer 2003). In addition, Wilson (1998) included largescale volcanic eruptions in an assessment of influences on annual temperatures from the Armagh Observatory, Northern Ireland, between 1818 and 1858, and found that high-magnitude volcanic eruptions led to reduced Irish temperatures in the year following the eruption. This is the first study to systematically explore and identify the impacts of multiple volcanic eruptions on the Irish temperature record over the last 200 years.

In this study, daily temperature data from the Armagh Observatory were used to examine the impact for Ireland of five high-magnitude low-latitude eruptions and one Icelandic event. The large low-latitude eruptions included in this analysis are known to have had an influence on global climate (Briffa et al. 1998). The Icelandic eruption is included due to the fact that it was the highest magnitude volcanic eruption in relatively close proximity to Ireland during the timeframe provided by the data.

\section{Volcanic impacts on temperature}

Low-latitude high-magnitude volcanic eruptions that penetrate the stratosphere can have a notable impact on global climate due to the ease with which the volcanic particles can circulate in the atmosphere (Robock and Free 1995), whereas ejecta from eruptions that occur at higher latitudes will remain concentrated in the hemisphere within which they were injected (Oman et al. 2005). The gases produced by eruptions affect the earth's climate through a set of complex interactions. These gases are dominated by water vapour and carbon dioxide $(\sim 80 \%$ and $10 \%$ respectively), with the remaining $10 \%$ composed of between five and eight other gases and aerosols depending on the parent material, the most common of which tends to be sulphur dioxide $\left(\mathrm{SO}_{2}\right)$. Aerosols have a more notable, long-term influence on climate than ash, as the larger material falls out of the stratosphere relatively quickly following volcanic eruptions. This results in their influence on local climate being short-lived, while a more widespread effect is nonexistent. Robock and Mass (1982), after the 1980 Mount St. Helens eruption in Washington, showed that this temporary atmospheric loading significantly reduced the amplitude of the diurnal cycle of surface air temperature in the region of the ash cloud. However, these effects disappear as soon as the large particles of ash settle on the ground (Robock 2000). This removal is the result of the gravitational fall of the particles, or their washout by precipitation. The $\mathrm{SO}_{2}$ emissions from this particular eruption were too small to produce any far-reaching climatic effects (Rampino et al. 1988).

Only larger Plinian-style pyroclastic eruptions such as Mount Pinatubo in 1991 penetrate the tropopause and the stratosphere. This facilitates the distribution of particles in a drier layer of the atmosphere and reduces the likelihood of the emissions being rained out (de Silva 2005). The aerosols produced have an atmospheric residence time of one to three years, depending on the latitude and 
altitude of the initial injection (Robock 2000). Because the increased concentration of volcanic aerosols remains in the stratosphere, they act to reduce temperatures in the layers below, that is, the troposphere and the earth's surface. Aerosols limit sunlight reaching these levels and essentially increase the albedo effect in the atmosphere (Pollack et al. 1976). In addition, volcanic aerosols cause destruction of ozone as a result of heterogeneous reactions with anthropogenic chlorine species (Kirchner et al. 1999). This results in less UV absorption in the stratosphere, which in turn modifies the aerosol heating effect (Rosenfield et al. 1997). Simulations of temperature changes within the troposphere associated with the El Chichón eruption in 1982 (Pollack et al. 1991) show that the solar perturbation is likely to see the cooling aspect becoming dominant in the months and years following an eruption.

\section{Data and methods}

The data analysed was obtained from Armagh Observatory, Co. Armagh $\left(54^{\circ} 21^{\prime} \mathrm{N}\right.$; $6^{\circ} 38^{\prime} \mathrm{W}$ ), which lies approximately $1 \mathrm{~km}$ northeast of Armagh city centre. It is situated $64 \mathrm{~m}$ above mean sea level in an estate of natural woodland and parkland. The observatory is largely surrounded by countryside similar to that which has existed since its foundation in 1790 (Butler et al. 2005). The surrounding rural environment has ensured that the observatory suffers from little or no urban microclimatic effects (Coughlin and Butler 1998). In addition, at a wind exposed site, urban climatic effects are likely to be minimised (Butler et al. 2005). All temperature data was acquired from Butler et al.'s (2005) mean daily temperatures from Armagh Observatory for the years 1796-2007.

\section{Selection of eruptions}

Large volcanic eruptions from higher latitudes, such as Ksudach on the Kamchatka Peninsula in Russia in 1907, were not included in the analysis as climatic impacts outside of their immediate regions are not well defined (Oman et al. 2005). Lowlatitude eruptions that occurred after the establishment of the Armagh weather records, that is January 1796, were the main focus for this study, while highmagnitude Icelandic events were also considered. The choice of eruptions for analysis was narrowed further when only those with a Volcanic Explosivity Index (VEI) value of at least 5 (after Newhall and Self 1982) were chosen. VEI provides a relative measure of the explosiveness of volcanic eruptions. The scale ranges from 0 for nonexplosive eruptions (less than $10^{4} \mathrm{~m}^{3}$ of tephra ejected with an eruption column height of less than $100 \mathrm{~m}$ ) to 8 for mega-colossal (explosive eruptions that eject $10^{12}$ $\mathrm{m}^{3}$ of tephra and have a cloud height of over $25 \mathrm{~km}$ ).

The number of VEI $\geq 5$ eruptions selected was reduced by the requirement of the wider impact upon Northern Hemisphere climate being acknowledged in the literature. For example, the VEI 5 eruption of Mount Agung in Bali in 1963 had a very small volume of ejecta. Four fifths of this was spread throughout the Southern Hemisphere which in turn failed to produce an effect in the Northern Hemisphere (Rampino et al. 1988). Similarly, the 1902 VEI 6 eruption of Santa Maria in Guatemala was discounted as Briffa et al. (1998) pointed out that the event was not influential in their analysis of Northern Hemisphere temperature change, while Hammer et al. (1980) came to the same conclusion based on ice-core records. Mass 
and Portman (1989) suggest that this lack of influence could be due to the impact of El Niño Southern Oscillation (ENSO) on regional wind patterns at that time. The selection of the Icelandic eruptions was based on similar criteria to those of a lowlatitude origin. Here, eruptions since 1796 with a VEI $\geq 5$ were selected. Only one such eruption, Askja in 1875, occurred in Iceland during this time. All information regarding VEI values was acquired from the Smithsonian Institution's Global Volcanism Program (Siebert and Simkin 2002). The locations of the relevant volcanoes can be seen in Figure 1.

\section{Data analysis}

Natural variability in climate is caused by changes in solar output, volcanic activity, and internal interactions between the various components of the climate system, that is, the atmosphere, ocean, cryosphere and biosphere (Slonosky et al. 2001). Particularly cold conditions have been linked to variations in solar output in the form of decreased sunspot activity, which limits the amount of solar radiation reaching the earth (Lean et al. 1995), while the North Atlantic Oscillation (NAO) is regarded as one of the primary influences upon climatological variability in Western and Northwestern Europe (Hurrell 1995). Consequently, this paper employs linear regression analysis to individually assess the influence of each of these three forcing factors upon the Armagh Observatory temperature series. This analysis was carried out based on non-overlapping five-year means in an effort to reduce the effect of delayed spatial responses and slight dating uncertainties in terms of volcanic eruptions (Briffa et al. 1998). Table 1 reports the standardised and unstandardised beta values for regressions run between seasonal temperatures and NAO, sunspot and Dust Veil Index (DVI) values. It also highlights the adjusted $\mathrm{R}^{2}$ values achieved from these multiple regressions, as well as the change in the $\mathrm{R}^{2}$ value that occurs when the influence of the DVI is added to the combined influence of NAO and sunspots (Mass and Portman 1989). The influence of NAO was assessed using Luterbacher et al.'s (2002) reconstructed monthly values, while the mean monthly sunspot data employed, the International Sunspot Number, was compiled by the Solar Influences Data Analysis Centre (2011). Finally, Lamb's (1970) DVI, perhaps the best indicator of global volcanic activity (Robock 1983, Lough and Fritts 1987) was used to gauge the impact volcanic eruptions have had on the Armagh Observatory temperature series.

Monthly residual temperature series were created whereby the influences of NAO and sunspots were factored out, leaving residuals that were more closely associated with variations attributed to volcanic eruptions. An adapted version of Superposed Epoch Analysis (SEA) was used to analyse the residual temperatures in an effort to identify a volcanic signal. SEA resolves signal to noise problems associated with volcanic events where the climatological response may be masked or accentuated by noise from other variables (Bradley 1988, Donarummo et al. 2002, Adams et al. 2003). However, because the number of volcanic eruptions under examination here is relatively small, it was necessary to adapt the normally large-scale approach of SEA to accommodate the reduced $\mathrm{N}$ value. The process involves sorting data into categories dependent on a key-date for synchronisation and then comparing the means of those categories (Adams et al. 2003). In each case, the key-date was the year within which the eruption occurred. For example, in the case of the eruption of 


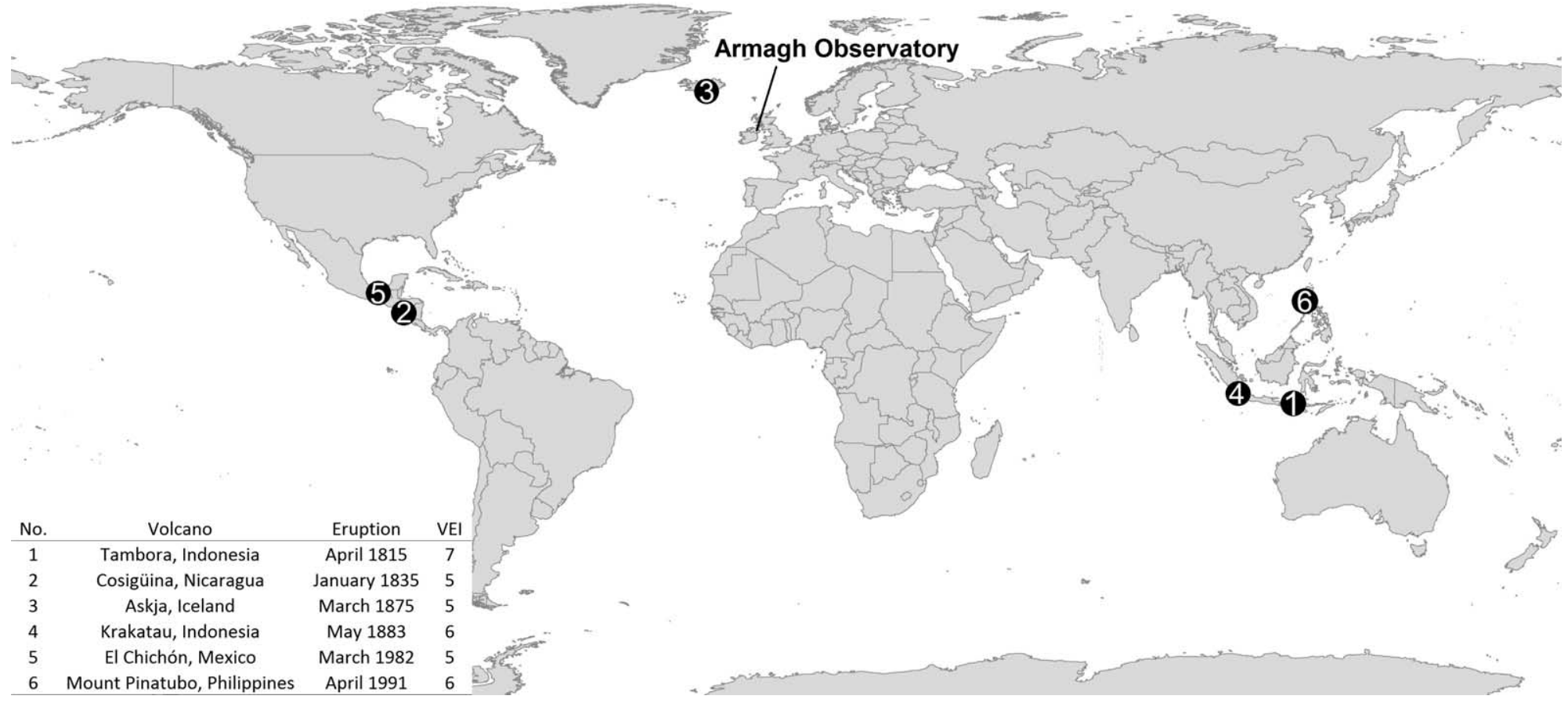

Figure 1. Names, locations, eruption dates and Volcanic Explosivity Index (VEI) values of six chosen volcanic eruptions. 
Table 1. Beta and adjusted $\mathrm{R}^{2}$ values from multiple regression involving mean seasonal temperature data from Armagh Observatory and NAO, sunspot and DVI values in 5-year non-overlapping means.

\begin{tabular}{|c|c|c|c|c|c|c|c|c|}
\hline \multirow[b]{2}{*}{ Seasonal temperature (5-yr groupings) } & \multicolumn{2}{|c|}{ Winter } & \multicolumn{2}{|c|}{ Spring } & \multicolumn{2}{|c|}{ Summer } & \multicolumn{2}{|c|}{ Autumn } \\
\hline & $\beta$ & $\beta$ Std & $\beta$ & $\beta$ Std & $\beta$ & $\beta \mathrm{Std}$ & $\beta$ & $\beta$ Std \\
\hline Seasonal NAO & $0.637 * *$ & $0.438^{* *}$ & 0.150 & 0.128 & -0.047 & -0.037 & -0.178 & -0.101 \\
\hline Seasonal sunspot & 0.006 & 0.313 & $0.008^{*}$ & $0.419^{*}$ & 0.006 & 0.285 & $0.010^{* *}$ & $0.513^{* *}$ \\
\hline DVI & $-0.003 * *$ & $-0.515^{* *}$ & $-0.003 *$ & $-0.443^{*}$ & -0.001 & -0.162 & -0.002 & -0.341 \\
\hline & \multicolumn{2}{|c|}{$0.419^{* *}$} & \multicolumn{2}{|c|}{$0.295^{* *}$} & \multicolumn{2}{|c|}{0.024} & \multicolumn{2}{|c|}{$0.284^{*}$} \\
\hline $\mathrm{R}^{2}$ change following inclusion of DVI & \multicolumn{2}{|c|}{$0.242^{* *}$} & \multicolumn{2}{|c|}{$0.179^{*}$} & \multicolumn{2}{|c|}{0.000} & \multicolumn{2}{|c|}{0.098} \\
\hline
\end{tabular}

* Correlation significant at the $95^{\text {th }}$ percentile

** Correlation significant at the $99^{\text {th }}$ percentile 
Tambora in April 1815, the key spring, summer and autumn dates were those from 1815, while the winter key date was December-February 1815-1816. For each of the six key dates (from each eruption selected), an 11-year window centred on the key date (year 0) was extracted from the mean seasonal residual indices and centred into the adapted SEA matrix. This provides a reasonable interval for resolving a response to volcanic forcing ( $\sim 5$ years). Three-year composites were employed whereby independent samples T-tests were used to determine statistical significance. Given the potential seasonal lags in response to volcanic forcing, SEA will provide its strongest results when performed in such multi-year composites (Adams et al. 2003). Each possible combination of consecutive three-year groups (from TY-5 to TY +5 ), moving in one year steps, were re-sampled in block form against the remainder of the matrix. Table 2 contains the significantly positive/negative results achieved during these tests, while also showing the positive/negative results when the same independent samples T-tests were applied to the recorded mean seasonal temperature values in Armagh Observatory.

\section{Seasonal yearly volcano-induced change}

Briffa et al. (1998) put forward the theory that the most intense period of cooling following volcanic eruptions occurs in the first summer after the event. In an effort to examine this in terms of the data from Armagh Observatory, the residual and recorded seasonal temperature for the year of events (TY) to the fourth year after the events $(\mathrm{TY}+4)$ was expressed as an anomaly from the 10 -year mean of the corresponding seasons prior to the eruptions. The use of a 10-year mean has the advantage of being sufficiently long to remove much of the inter-annual variation, while also being short enough to reflect long-term climate trends (Mass and Portman 1989). A similar theory of predicted change in post-eruption temperatures was proposed by Robock and Mao (1992), who postulated that an increase in concentrations of particulate matter and aerosols in the atmosphere acts to increase temperatures in the winter period following eruptions. Again, deviations from the 10year mean of the corresponding seasons prior to the eruptions were calculated to highlight when/if any increase in winter temperatures can be expected. To ensure complete seasonal coverage, the same method of analysis was applied to mean spring and autumn residual and recorded temperatures from Armagh Observatory, as well as mean yearly values. The mean changes over the six selected eruptions, in addition to the standard deviation for each year, are presented in Figure 2.

\section{Results}

The standardised and unstandardised beta values in Table 1 show the strengths of the relationships between each of the three forcing factors (NAO, sunspots and DVI) and the temperature values from Armagh Observatory in terms of five-year nonoverlapping means. As would be expected, the strongest relationship between NAO and temperatures occurs in winter, with significantly positive beta values. However, these values are overshadowed by the negative results returned when the influence of Lamb's (1970) Dust Veil Index is assessed. A standardised beta value of -0.515 is achieved with winter temperatures, while spring temperatures in Armagh Observatory return a standardised beta value of -0.443 . The number of sunspots during 
Table 2. Adapted 3-year Superposed Epoch Analysis. Years with negative 3-year composites at the 95\% and 99\% confidence level are marked by N* and $\mathrm{N}^{* *}$ respectively. Resid.: Residual temperature; Rec.: Recorded temperature.

\begin{tabular}{|c|c|c|c|c|c|c|c|c|c|c|c|c|c|c|c|c|c|c|}
\hline & \multicolumn{2}{|c|}{-5 to -3} & \multicolumn{2}{|c|}{-4 to -2} & \multicolumn{2}{|c|}{-3 to -1} & \multicolumn{2}{|c|}{-2 to 0} & \multicolumn{2}{|c|}{-1 to 1} & \multicolumn{2}{|c|}{0 to 2} & \multicolumn{2}{|c|}{1 to 3} & \multicolumn{2}{|c|}{2 to 4} & \multicolumn{2}{|c|}{3 to 5} \\
\hline & Resid. & Rec. & Resid. & Rec. & Resid. & Rec. & Resid. & Rec. & Resid. & Rec. & Resid. & Rec. & Resid. & Rec. & Resid. & Rec. & Resid. & Rec. \\
\hline Winter & & & & & & & & & & & & & & & $\mathrm{N}^{*}$ & $\mathrm{~N}^{*}$ & & \\
\hline Spring & & & & & & & & & & & & & $\mathrm{N}^{* *}$ & $\mathrm{~N}^{* *}$ & $\mathrm{~N}^{* *}$ & $\mathrm{~N}^{* *}$ & & \\
\hline \multicolumn{19}{|l|}{ Summer } \\
\hline Autumn & & & & & & & & & & & & & & & & & & \\
\hline Year & & & & & & & & & & & & & $\mathrm{N}^{*}$ & $\mathrm{~N}^{*}$ & $\mathrm{~N}^{*}$ & & & \\
\hline
\end{tabular}

* Correlation significant at the $95^{\text {th }}$ percentile

** Correlation significant at the 99th percentile 

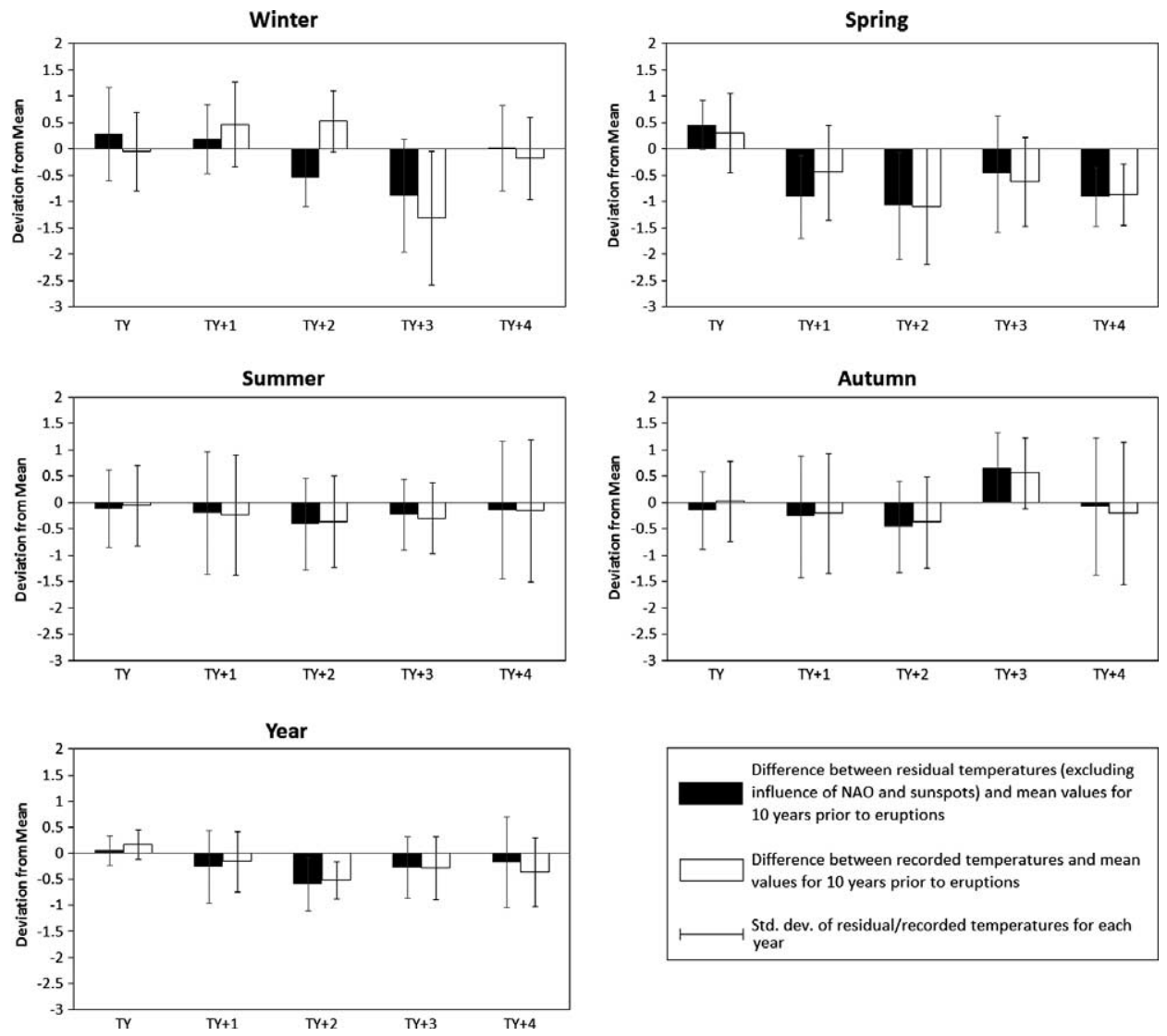

Figure 2. Seasonal and yearly residual and recorded temperature deviations from the 10-year mean prior to eruptions in the year of events (TY) and the four years following $(\mathrm{TY}+x)$ events.

spring has an almost equal, but opposite, influence on temperature ( $\beta$ Std: 0.416). None of the three forcing factors examined returned a significant beta value during the summer months, while the DVI was, again, the most influential factor in autumn with a standardised beta value of 0.513 . The adjusted $\mathrm{R}^{2}$ values in Table 1 show that, when combined, the influence of NAO, sunspots and DVI on temperatures in Armagh Observatory is at its strongest in winter $\left(\mathrm{R}^{2}: 0.419\right)$, followed by spring and autumn. These forcing factors have no significant impact on summer temperature, either individually or when combined. The strong standardised beta relationship between winter temperatures and DVI is emphasised again by the increase that occurs in the $\mathrm{R}^{2}$ value $(+0.242)$ when DVI is added to a multiple regression involving NAO and sunspots. Again, spring values are also increased, but to a lesser extent, while autumn $\mathrm{R}^{2}$ values increased only marginally when the influence of DVI is included.

The results in Table 2 indicate that the season within which the residual temperatures in Armagh Observatory is most significantly negatively affected following volcanic eruptions is spring. Here, the three-year intervals between 
$\mathrm{TY}+1$ to $\mathrm{TY}+3$ and $\mathrm{TY}+2$ to $\mathrm{TY}+4$ contain negative correlations significant at the $99^{\text {th }}$ percentile signifying that temperatures can be expected to fall during spring in the year after a high-magnitude volcanic eruption, and remain significantly lower than normal until the fourth year after such an event. The same is true for the recorded temperatures in Armagh Observatory, the series within which the influence of NAO and sunspots has not been reduced. Residual winter temperatures are negatively affected, with a significance at the $95^{\text {th }}$ percentile, in the three-year interval of $\mathrm{TY}+2$ to $\mathrm{TY}+4$, while residual yearly mean temperatures see a similar scale reduction in values during the time period of $\mathrm{TY}+1$ to $\mathrm{TY}+3$. The same trend is identified in the recorded mean yearly temperature values, and continues into the $\mathrm{TY}+2$ to $\mathrm{TY}+4$ interval.

Figure 2 shows the mean changes that occurred in seasonal and yearly residual and recorded temperatures in the year of, and four years following, the six highmagnitude volcanic eruptions. As with the SEA, it is immediately apparent that spring values are negatively affected more than any other season in the years following the selected eruptions. The mean changes in the four years after events are consistently below the mean value for 10 years prior to eruptions, with the standard deviations for $\mathrm{TY}+1, \mathrm{TY}+2$ and $\mathrm{TY}+4$ indicating that the spread of individual values is focused below the mean. In each of these years, the mean reduction in residual spring temperatures is at least $0.9^{\circ} \mathrm{C}$. The slight increase in mean residual winter temperatures in the year of and year after eruptions is followed by progressively colder conditions over the following two years, with reductions of, on average, $0.8^{\circ} \mathrm{C}$ and $1.1^{\circ} \mathrm{C}$. Winter in $\mathrm{TY}+2$ is the only season in the analysis where the residual and recorded temperatures clearly move in opposite directions. This emphasises the strong influences the NAO and volcanic eruptions can have on values as, when looked at separately, there is a markedly different reaction. The response of summer temperatures, both residual and recorded, shows that they remain just below the mean in each of the five years examined. However, the standard deviations indicate that the spread of individual results during the summer months can be quite broad, with no notable trends of individual results being concentrated above or below the 10-year mean. Similarly, the standard deviations for the residual and recorded autumn temperature values show that although there is a tendency for mean values to be somewhat below average in all but $\mathrm{TY}+3$, the individual results were divided between positive and negative responses. Finally, the mean yearly temperature records show that $\mathrm{TY}+1$ to $\mathrm{TY}+4$ are, on average, negatively affected, yet it is only in the second year after eruptions that the standard deviations remain concentrated below the mean for both recorded and residual temperatures.

\section{Discussion}

Briffa et al.'s (1998) theory of intense cooling in the first summer following volcanic eruptions is not supported by the evidence provided by the temperature series in Armagh Observatory. Both the residual and recorded temperature series show only a slight mean decrease in TY +1 (Figure 2). With neither the regression analysis in Table 1 nor the Superposed Epoch Analysis in Table 2 producing significant correlations for summer months, it is clear that, on average, any volcano-induced changes experienced in Armagh at this time of year are minimal. Instead, the most 
notable and sustained decrease in temperatures following eruptions occurs in the spring months. The temperatures in Armagh tended to rise in the year of an event, suggesting that the eruptions, all of which occurred within the first four months of the year, did not have sufficient time to bring about a reduction in values in TY (the sole decrease in residual temperatures came during the spring immediately after the January 1835 Cosigüina eruption). Both the strongly negative standardised beta value of the regression analysis in Table 1, and the consecutive significantly negative results in the adapted composite Superposed Epoch Analysis in Table 2, indicate that spring temperatures will be persistently reduced in the wake of high-magnitude volcanic eruptions. This spring cooling, according to Stenchikov et al. (2002), is as a result of substantial changes in ozone levels following strong explosive volcanic eruptions. Ozone absorbs solar UV radiation, and radiates and absorbs thermal IR radiation. Volcanically-induced depletions in ozone levels cause cooling in higher latitudes in spring because of a decrease in UV absorption. The net contribution from the IR effect is smaller and as a result the most notable period of cooling tends to occur in spring (Stenchikov et al. 2002). The standard deviations for residual spring temperatures in $\mathrm{TY}+1$ indicate that, individually, the eruptions examined were dominated by particularly lower than normal temperatures (Figure 2). This dominance continues in the residual temperatures in $\mathrm{TY}+2$, where the recorded values in Armagh follow the same pattern.

The mean changes in recorded winter temperatures indicate a slight decrease in values in winter in the year of a high-magnitude eruption. However, the filtering of NAO and sunspot influence from the dataset shows a mean increase in residual temperatures in TY, as was hypothesised by Robock and Mao (1992). Four of the six eruptions examined coincided with warmer than normal temperatures in the first winter after the events. This, according to Shindell et al. (2004) is the result of a dynamic response to the presence of volcanic aerosols in the atmosphere. The aerosols heat the sunlit portions of the stratosphere, enhancing the pole-to-equator temperature gradient through the thermal wind relationship (Robock 2003). The newly strengthened low-level stratospheric westerlies pass down to the troposphere via interactions with planetary waves to enhance surface-level westerlies, in turn acting to increase temperatures to above the norm (Shindell et al. 2004). This increase in values persists in $\mathrm{TY}+1$, and is replaced by notably lower residual temperatures in the following two years (Figure 2), an occurrence that also leads to a significant negative change being highlighted in the $\mathrm{TY}+2$ to $\mathrm{TY}+4$ adapted Superposed Epoch Analysis for winter (Table 2). As the concentration of volcanic aerosols in the stratosphere dissipates in the years following events, so too does the enhanced pole-to-equator temperature gradient, the enhanced westerly winds and, in turn, the increased winter temperatures. At this point, the interaction between volcanic aerosols and ozone that dominates spring temperature values begins to become prevalent in the winter records (Stenchikov et al. 2002).

The standard deviations of the recorded and residual autumn temperatures show a quite varied response at this time of year in terms of individual volcanic eruptions (Figure 2). Only TY +3 indicates any consistency in trends, where five of the six residual values and four recorded mean temperatures were above the 10-year mean. However, this trend may not be volcanically induced as the increase in values comes in the same year that the warming influence on winter temperatures has been notably reversed, and the colder spring values have waned. Similar to the summer 
temperatures in Armagh, little volcano-induced change seems to manifest in the autumn data.

The process of filtering the influence of the NAO and sunspots from the Armagh Observatory temperature series proved successful. Table 1 indicates the stark contrast between NAO and volcanic eruptions in terms of mean winter temperatures, where similar but opposite reactions were recorded. A similar trend occurred in spring, but the influence of the DVI was much stronger at this time of year. For the most part, the residual and recorded temperatures followed the same patterns (Figure 2). However, the disparity in $\mathrm{TY}+2$ winter values underlines the success of the filtering process by presenting the marked difference that would have occurred had one or the other forcing factors not been present. The significant negative impact in TY +2 to TY +4 shown in the adapted Superposed Epoch Analysis for recorded temperatures did not register when the NAO and sunspots had been filtered out. Although the recorded values displayed a pattern that appeared significant, the removal of the 'false' signal with this small of a sample size proved important.

\section{Conclusion}

The timing of the impacts of volcanic eruptions on the Armagh temperature series suggests that the dynamic influence of the aerosols in the atmosphere has the most notable impact on Irish temperatures. The aerosols' manipulation of planetary waves and ozone levels manifests most notably in spring temperatures. Consecutive mean reductions in residual spring temperatures of $0.9^{\circ} \mathrm{C}, 1.1^{\circ} \mathrm{C}$ and $0.5^{\circ} \mathrm{C}$ between $\mathrm{TY}+1$ and $\mathrm{TY}+3$ compare favourably with values that come between $0.2^{\circ} \mathrm{C}$ and $0.5^{\circ} \mathrm{C}$ (Self et al. 1981). Meanwhile the hypothesised initial increase in winter values is also a feature of the dataset, but this is quickly replaced by a dominant cooling trend in the remainder of the winters examined. In contrast, the purely radiative impacts of volcanic aerosols that dominate at lower latitudes during summer months fail to bring about any notable changes at this time of year in Armagh. The concentration of particulate matter in the stratosphere over Ireland is not enough to trigger a significant increase in atmospheric albedo, yet the impact upon ozone levels and planetary waves is sufficiently strong to transfer to Armagh Observatory's temperature dataset.

\section{Acknowledgements}

The authors wish to thank Prof. Chris Caseldine and Prof. Micheál O'Cinneide, as well as the anonymous reviewers, for their helpful comments and feedback on content and form. Thanks also to Ligang Dao for producing Figure 1. We also wish to acknowledge funding received from the COIMBRA group during the course of this research.

\section{References}

Adams, J.B., Mann, M.E., and Ammann, C.M., 2003. Proxy evidence for an El Niño-like response to volcanic forcing. Nature, 426 (6964), 274-278.

Bradley, R.S., 1988. The explosive volcanic eruption signal in Northern Hemisphere continental temperature records. Climatic Change, 12 (3), 221-243. 
Briffa, K.R., Jones, P.D., Schweingruber, F.H., and Osborn, T.J., 1998. Influence of volcanic eruptions on Northern Hemisphere summer temperature over the past 600 years. Nature, 363 (6684), 450-455.

Butler, C.J., García-Suárez, A.M., Coughlin, A.D.S., and Morrell, C., 2005. Air temperatures at Armagh Observatory, Northern Ireland, from 1796 to 2002. International Journal of Climatology, 25 (8), 1055-1079.

Coughlin, A.D.S. and Butler, C.J., 1998. Is urban spread affecting the mean temperature at Armagh Observatory? Irish Astronomy Journal, 25 (2), 125-128.

de Silva, S.L., 2005. Volcanic eruptions and their impact on the earth's climate. In: J. Oliver, ed., Encyclopaedia of world climatology. Dordrecht: Springer, 788-793.

Donarummo, J., Ram, M., and Stolz, M.R., 2002. Sun/dust correlations and volcanic interference. Geophysical Research Letters, 29 (9), 1361.

Hammer, C.U., Clausen, H.B., and Dansgaard, W., 1980. Greenland ice sheet evidence of post-glacial volcanism and its climatic impact. Nature, 288 (5788), 230-235.

Hurrell, J.W., 1995. Decadal trends in the North Atlantic Oscillation: Regional temperatures and precipitation. Science, 269 (5224), 676-679.

Kirchner, I., Stechnikov, G.L., Graf, H.F., Robock, A., and Antuna, J.C., 1999. Climate model simulation of winter warming and summer cooling following the 1991 Mount Pinatubo volcanic eruption. Journal of Geophysical Research, 104 (D16), 19039-19055.

Lamb, H.H., 1970. Volcanic dust in the atmosphere; with a chronology and assessment of its meteorological significance. Philosophical Transactions of the Royal Society of London A, 266 (1178), 425-533.

Lean, J., Beer, J., and Bradley, R., 1995. Reconstruction of solar irradiance since 1610: Implications for climate change. Geophysical Research Letters, 22 (23), 3195-3198.

Lough, J.M. and Fritts, H.C., 1987. An assessment of the possible effects of volcanic eruptions on North American climate using tree-ring data, 1602-1900 A.D. Climate Change, 10 (3), 219-239.

Luterbacher, J., Xoplaki, E., Dietrich, D., Rickli, R., Jacobeit, J., Gyalistras, D., Schmutz, C., and Wanner, H., 2002. Reconstruction of sea level pressure fields over the Eastern North Atlantic and Europe back to 1500. Climate Dynamics, 18 (7), 545-561.

Mass, C. and Portman, D., 1989. Major volcanic eruptions and climate: A critical evaluation. Journal of Climate, 2 (6), 566-593.

Newhall, C.G. and Self, S., 1982. The volcanic explosivity index (VEI): An estimate of explosive magnitude for historical volcanism. Journal of Geophysical Research, 87 (C2), $1231-1238$.

Ogle, N., Turney, C.S.M., Kalin, R., O’Donnell, L., and Butler, C.J., 2005. Palaeovolcanic forcing of short-term dendroisotopic depletion: The effect of decreased solar intensity on Irish oak. Geophysical Research Letters. 32 (4) L04708.

Oman, L., Robock, A., Stenchikov, G., Schmidt, G.A., and Ruedy, R., 2005. Climatic response to high-latitude volcanic eruptions. Journal of Geophysical Research, 110 (D13103).

Oppenheimer, C., 2003. Climatic, environmental and human consequences of the largest known historic eruption: Tambora volcano (Indonesia) 1815. Progress in Physical Geography, 27 (2), 230-259.

Písek, J. and Brázdil, R., 2006. Responses of large volcanic eruptions in the instrumental and documentary data over Central Europe. International Journal of Climatology, 26 (4), 439459.

Pollack, J.B., Sagan, C., Summers, A., Baldwin, B., and Van Camp, W., 1976. Volcanic explosions and climatic change: A theoretical assessment. Journal of Geophysical Research, 81 (6), 1071-1083.

Pollack, J.B., Witteborn, F.C., O'Brien, K., and Flynn, B., 1991. A determination of the infrared optical depth of the El Chichón volcanic cloudf. Journal of Geophysical Research, 96 (D2), 3115-3122.

Pollack, J.B., Rind, D., Lacis, A., Hansen, A.E., Sato, M., and Ruedy, R., 1993. GCM simulations of volcanic aerosol forcing. Part I: climate changes induced by steady-state perturbations. Journal of Climate, 6 (9), 1719-1742.

Rampino, M.R., Self, S., and Stothers, R., 1988. Volcanic winters. Annual Review Earth Planetary Science, 16, 73-99. 
Robock, A., 1983. The dust cloud of the century. Nature, 301 (5899), 373-374.

Robock, A., 2000. Volcanic eruptions and climate. Reviews of Geophysics, 38 (2), 191-219.

Robock, A., 2003. Volcanoes: Role in climate. In: J. Holton, J.A. Curry and J. Pyle, eds. Encyclopedia of Atmospheric Sciences. London: Academic Press, 2494-2500.

Robock, A. and Free, M., 1995. Ice cores as an index of global volcanism from 1850 to the present. Journal of Geophysical Research, 100 (D6), 11549-11567.

Robock, A. and Liu, Y., 1994. The volcanic signal in Goddard Institute for Space Studies three-dimensional model simulations. Journal of Climate, 7 (1), 44-55.

Robock, A. and Mao, J., 1992. Winter warming from large volcanic eruptions. Geophysical Research Letters, 12, 2405-2408.

Robock, A. and Mass, C., 1982. The Mount St. Helens Volcanic Eruption of May 1980: Large short-term surface temperature effects. Science, 216 (4546), 628-630.

Rosenfield, J., Considine, D., Meade, P., Bacmeister, J., Jackman, C., and Schoeberl, M., 1997. Stratospheric effects of Mount Pinatubo aerosol studied with a coupled two-dimensional model. Journal of Geophysical Research, 102 (D3), 3649-3670.

Self, S., Rampino, M., and Barbera, J.J., 1981. The possible effects of large $19^{\text {th }}$ and $20^{\text {th }}$ century volcanic eruptions on zonal and hemispheric surface temperatures. Journal of Volcanology and Geothermal Research, 11 (1), 41-60.

Shindell, D.T., Schmidt, G.A., Mann, M.E., and Faluvegi, G., 2004. Dynamic winter climate response to large tropical volcanic eruptions since 1600. Journal of Geophysical Research, 109 (D05104).

Siebert, L. and Simkin, T., 2002. Volcanoes of the world: An illustrated catalogue of Holocene volcanoes and their eruptions [online]. Smithsonian Institution, Global Volcanism Program Digital Information Series, GVP-3. Available from: http://www.volcano.si.edu/world/largee ruptions.cfm [Accessed 14 July, 2008].

Slonosky, V.C., Jones, P.D., and Davies, T.D., 2001. Atmospheric circulation and surface temperature in Europe from the $18^{\text {th }}$ century to 1995. International Journal of Climatology, $21(1), 63-75$.

Solar Influences Data Analysis Centre (SDIC), 2011. International sunspot numbers [online]. Available from: http://solarscience.msfc.nasa.gov/greenwch/spot_num.txt [Accessed 24 February 2011].

Stenchikov, G., Robock, A., Ramaswamy, V., Schwarzkopf, MD., Hamilton, K., and Ramachandran, S., 2002. Arctic Oscillation response to the 1991 Mount Pinatubo eruption: Effects of volcanic aerosols and ozone depletion. Journal of Geophysical Research. 107 (D24), 4803.

Wilson, R.M., 1998. Volcanism, cold temperature, and paucity of sunspot observing days (18181858): a connection? Alabama: Marshall Space Flight Centre, NASA/TP-1998.

Zielinski, G.A., 2000. Use of paleo-records in determining variability within the volcanismclimate system. Quaternary Science Reviews, 19 (1-5), 417-438. 